\title{
EDUCATIONAL PROJECTS AS INTAGIBLES' RESOURCE ALLOCATION: AN AHP APPROACH
}

\begin{abstract}
The decisional making process was used in this paper for underlining the importance of the process of resource allocation in a student organization (NGO). By elaborating a decisional model using AHP and by having the specialized knowledge of educational experts, the projects and initiatives taken into consideration were optimally chosen, by individual questioning, the results being the same in each case. Thus, the decisional model is being perceived as a sustainable system of decision-making.
\end{abstract}

Keywords: AHP, project allocation, student organization, decisional model, optimization.

\section{Introduction}

Each person or company is experiencing difficulties in choosing the best. Persons with authority are experiencing a priority dilemma, the subjectivity and limitations putting them in a situation where they should choose responsibly and fast.

\section{Literature Review}

The AHP modeling is used all around the world in the field of education. In order to assess the institutional efficiency in a Mexican University, Corro and Verra (2014) proposed a mix of AHP and DEA modeling. For maximizing the university performance in Taiwan in terms of intellectual capital indicators, Lee used also an AHP model in 2010. Chen et al. proposed in 2015 a systematic framework having the goal of evaluating the teaching performance using AHP and comprehensive evaluation approach.

\section{Research Design/Methodology}

The design of a hierarchy crucially implies the weighted vector of alternatives' priorities considered in a decision problem. This paper illustrates the way through which the hierarchy itself can be validated if it is constructed and estimated by a group of relevant decision makers and embedded in a typical resource allocation optimization problem.

\section{Data/Model Analysis}

The project allocation problem within the student organization had to take into account the potential impact of the sensible alternatives as well as the general objectives, the mission and the vision of the organization itself. Thus, the intangible functions of the organization-constituting the principles of this structure (the organization, its needs for development, students interests and visibility of the projects) are the invisible yet decisive aspects to be taken into consideration when a certain project to be developed is weighted against another one. The schema below shows the result of the debate over the best hierarchy to illustrate the problem of choosing against different real projects this organization faces every year and the experts are its top five most important decision makers: the president, the three vice-presidents and the general secretary.

\begin{tabular}{|c|}
\hline The decisional problem: Project allocation \\
\hline Functions of the organization: Organizational Structure, Organization's \\
\hline
\end{tabular}

International Symposium on the

1

London, U.K.

Analytic Hierarchy Process

August 4 - August 7, 2016 


\begin{tabular}{|c|c|c|}
\hline \multicolumn{3}{|c|}{ needs for developing, Students Interests and Visibility of the Projects } \\
\hline $\begin{array}{r}\text { Departments, relationsh } \\
\text { benef }\end{array}$ & external parties and & Development \\
\hline $\begin{array}{l}\text { General and particular } \\
\text { interests of the students }\end{array}$ & $\begin{array}{l}\text { Main categories of } \\
\text { projects }\end{array}$ & $\begin{array}{l}\text { or projects in } \\
\text { time }\end{array}$ \\
\hline
\end{tabular}

The degree of the complexity of the model can be quickly glanced in the following print screen representing the problem implemented in the SuperDecisions software.

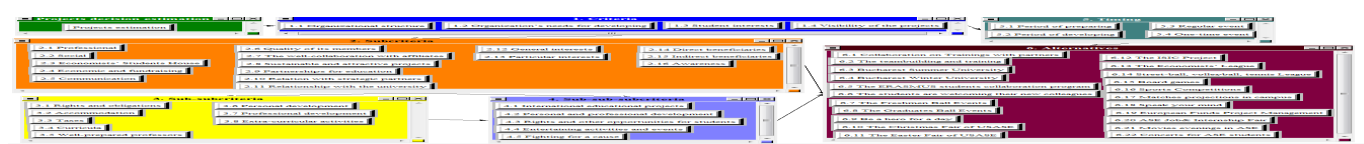

The homogeneity of the priority vectors among the five experts as resulted from the estimation of the synthetized priority vectors is illustrated in the figure below.
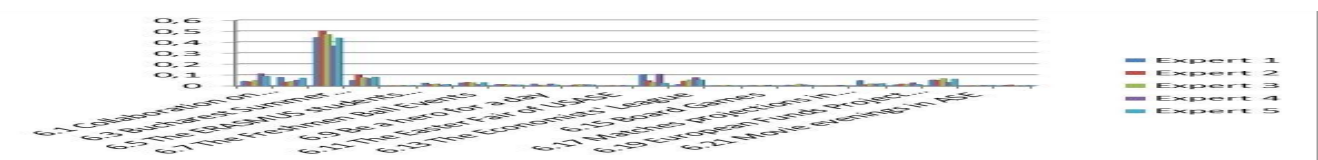

For every expert, their priority vectors interpreted as performances associated with the alternatives, together with the costs incurred by each of the considered projects were subject of an optimization problem as in the classical resource allocation problems. A value of " 1 ", corresponding to the associated decision variable indicated that the project under consideration is to be pursued. Below, it is shown that although there were differences in the weights of opinions among the five experts, the decisions rendered through individual appliance of the optimization problem were just identical.

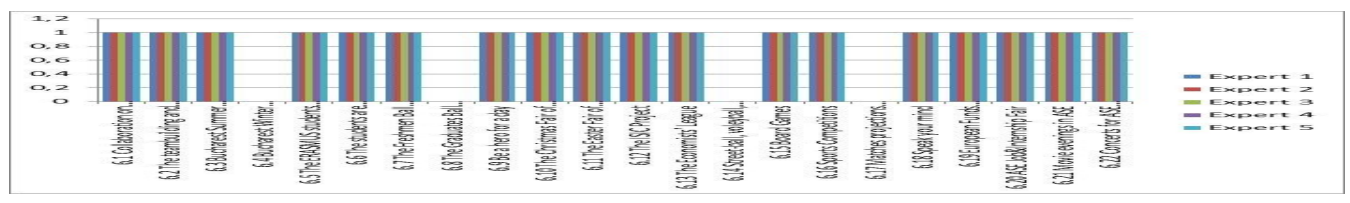

\section{Conclusions}

The innovative character of the decisional model implies that the student organization on in question is run by a unitary group and lead efficiently, not existing significant differences in the development policy of the association.

\section{Key References}

Chen J.F., Hsieh H.N., Do Q.H., 2015. Evaluating teaching performance based on fuzzy AHP and comprehensive evaluation approach. Applied soft computing, 28, 100-108;

Corro A.A., \& Peniche-Vera P., 2014. Measuring the institutional efficiency using DEA and AHP: the case of a Mexican University. Journal of applied research and technology, $12,63-71$.

Lee, S.H., 2010. Using fuzzy AHP to develop intellectual capital evaluation model for assessing their performance contribution in a university. Expert Systems with applications, 37, 4941-4947; 